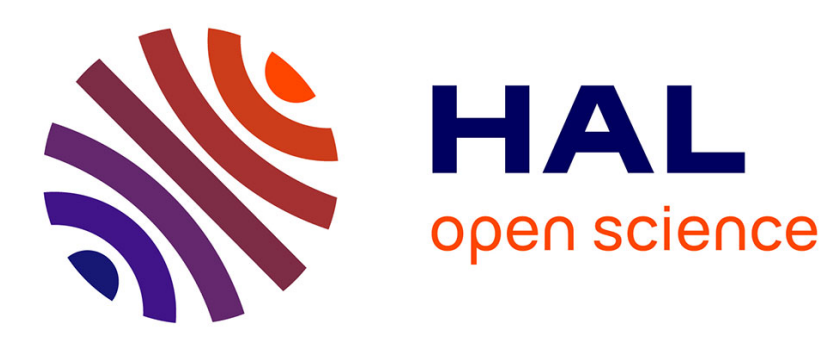

\title{
The glass transition of organic liquids confined to small pores
}

\author{
Catheryn L Jackson, Gregory B. Mckenna
}

\section{To cite this version:}

Catheryn L Jackson, Gregory B. Mckenna. The glass transition of organic liquids confined to small pores. Journal of Non-Crystalline Solids, 1991, 131-133, pp.221-224. 10.1016/0022-3093(91)90305-P . hal-02557806

\section{HAL Id: hal-02557806 https://hal.science/hal-02557806}

Submitted on 29 Apr 2020

HAL is a multi-disciplinary open access archive for the deposit and dissemination of scientific research documents, whether they are published or not. The documents may come from teaching and research institutions in France or abroad, or from public or private research centers.
L'archive ouverte pluridisciplinaire HAL, est destinée au dépôt et à la diffusion de documents scientifiques de niveau recherche, publiés ou non, émanant des établissements d'enseignement et de recherche français ou étrangers, des laboratoires publics ou privés. 


\title{
The glass transition of organic liquids confined to small pores
}

\author{
Catheryn L. Jackson and Gregory B. McKenna \\ Polymers Division, The National Institute of Standards and Technology, Gaithersburg, MD 20899, USA
}

\begin{abstract}
The glass-transition temperatures, $T_{\mathrm{g}}$, of organic liquids confined to small pores were studied by differential scanning calorimetry (DSC). The $T_{\mathrm{g}}$ was measured as a function of pore size in controlled pore glasses (CPG) having pore diameters in the range of $40-730 \AA$. The surface of the glass was treated with hexamethyldisilazane to promote wetting by the organic liquids studied (o-terphenyl and benzyl alcohol). Glasses formed in the pores had a lower $T_{\mathrm{g}}$ than in the bulk and the reduction in $T_{\mathrm{g}}$ increased as the pore size decreased. For example, the depression of the glass transition temperature, $\Delta T_{\mathrm{g}}$, of benzyl alcohol in $40 \AA$ and $85 \AA$ pores was $7.2 \mathrm{~K}$ and $3.1 \mathrm{~K}$, respectively. The magnitude of $\Delta T_{\mathrm{g}}$ also depends on the material; e.g. for o-terphenyl in the $85 \AA$ pores, $\Delta T_{\mathrm{g}}$ was $8.8 \mathrm{~K}$ versus $3.1 \mathrm{~K}$ for benzyl alcohol. In general, it was noted that $\Delta T_{\mathrm{g}}$ was considerably less than for the depression of the crystalline melting point, $\Delta T_{\mathrm{m}}$, studied in related work. For example, for benzyl alcohol in the $85 \AA$ pores, $\Delta T_{\mathrm{m}}$ was $\sim 25 \mathrm{~K}$ and $\Delta T_{\mathrm{g}}$ was $-3 \mathrm{~K}$.
\end{abstract}

\section{Introduction}

While it is well known that restricted geometries and small size have a significant effect on first-order phase transitions such as crystalline melting [1-3], solid-solid [3], and superfluidity [4] transitions, there has been little work performed to characterize the influence of these parameters on second-order or kinetic transitions, namely the liquid to glass transition [5-7]. This is in spite of the fact that the study of the behavior of glass-forming substances in confined geometries is of fundamental importance for several reasons beyond the comparison with the first-order behavior mentioned above. For example, it is possible that such studies could be used to differentiate among theories of the glass transition. Do free volume models [8-11] or entropy models $[12,13]$ better predict the influence of geometry and size on the magnitude of the glass transition? Are the kinetics [14] involved with glassy behavior altered due to size limitations? Can small size affect the molecular mobility of glasses [6,7,14-16]? Does the limitation of the 'size' of the liquid which forms the glass facilitate the glass-formation process and if so, why [5-7]?

In this paper we do not address all of these questions. However, we examine the role of system size on the glass-transition temperature and the change in the heat capacity at the glass transition. To do this, we present results from a study of two glass-forming organic liquids (ortho-terphenyl and benzyl alcohol) in controlled pore glasses having pore diameters, $d$, ranging from 40 to 730 $\AA$. We show that the glass-transition temperature decreases as pore size decreases, although not as much as does the melting point of the same materials. The $\Delta C_{p}$ at $T_{\mathrm{g}}$ is independent of pore size, unlike the apparent heat of fusion at the melting point [2]. The results are discussed in terms of current ideas of the glass-transition event.

Table 1

Controlled pore glass (CPG) properties

\begin{tabular}{lll}
\hline $\begin{array}{l}\text { Mean pore } \\
\text { diameter } \\
(\AA)\end{array}$ & $\pm \%^{\text {a) }}$ & $\begin{array}{l}\text { Pore } \\
\text { volume } \\
\left(\mathrm{cm}^{3} / \mathrm{g}\right)\end{array}$ \\
\hline 39.5 & 12.8 & 0.13 \\
85 & 13.5 & 0.59 \\
156 & 5.7 & 0.90 \\
255 & 3.7 & 0.96 \\
729 & 8.6 & 0.98 \\
\hline
\end{tabular}

a) $90 \%$ of the pore diameters are within this range.

b) determined by mercury intrusion method. 


\section{Experimental}

The controlled pore glasses (CPG) used in this study were supplied by Dr Wolfgang Haller of the National Institute of Standards and Technology [17]. The CPG is a white, free-flowing powder of $120 / 200$ mesh size. The mean pore diameter, the percentage of pores that are within $90 \%$ of this size, and the pore volume (in $\mathrm{cm}^{3}$ of liquid per $\mathrm{g}$ of glass) for each CPG were determined by mercury intrusion and are given in table 1 . The surface of the CPG was derivatized with hexamethyldisilazane to convert the surface hydroxyl groups to trimethylsilyl groups. This treatment makes the glass more hydrophobic and promotes wetting by organic liquids. The derivatization procedure is described elsewhere [2].

A Perkin-Elmer* differential scanning calorimeter (DSC-2C) was used, and the lowest achievable starting temperature was $140 \mathrm{~K}$ [2]. The DSC sample pans were large volume, stainless-steel pans (Perkin-Elmer* No. 0319-0218) sealed with an o-ring to prevent liquid loss. The CPG and organic material were weighed separately into the pre-weighed sample pan so that quantitative measurements could be made. The procedures for sample preparation and instrument calibration have been described elsewhere [2].

For o-terphenyl (1,2-diphenylbenzene), the quenched glass was prepared by heating well above the melting point ( $=329.3 \mathrm{~K}$ ) to $350 \mathrm{~K}$ for $15 \mathrm{~min}$ and then cooling at $10 \mathrm{~K} / \mathrm{min}$ to $190 \mathrm{~K}$. The $T_{\mathrm{g}} \mathrm{s}$ were then measured in heating scans at $10 \mathrm{~K} / \mathrm{min}$. For the benzyl alcohol, which is a liquid at room temperature (melting point $=257.9 \mathrm{~K}$ ) the glass was prepared by cooling at $5 \mathrm{~K} / \mathrm{min}$ to $140-150 \mathrm{~K}$ and then reheating at the same rate to obtain the $T_{\mathrm{g}} . \Delta T_{\mathrm{g}}$ is defined as the difference between the bulk $T_{\mathrm{g}}$ and the $T_{\mathrm{g}}$ at a given pore diameter measured at the midpoint of the transition range. Values of $\Delta C_{p}$ were also determined as a function of pore size for each material. For benzyl alcohol, $\Delta T_{\mathrm{m}}$ values were also determined as outlined elsewhere [2].

* Certain commercial companies are named in order to specify adequately the experimental procedure. This in no way implies endorsement or recommendation by NIST.

\section{Results}

The glass-transition temperature, $T_{\mathrm{g}}$, was observed to shift to lower temperatures when the system size was reduced by confining the liquid to small pores. A composite of the experimental data obtained for DSC scans for o-terphenyl confined in the pores of CPG with various pore diameters is shown in fig. 1 , with reference to the behavior of bulk, pure o-terphenyl. In the scans shown for the $85 \AA, 255 \AA$ and $730 \AA$ pore diameters, the pores are filled to roughly the expected maximum pore volume for a given size (table 1 ), and only one $T_{\mathrm{g}}$ is observed. For the o-terphenyl in the $40 \AA$ pores shown in fig. 1, the very large shift in $T_{\mathrm{g}}$ of 18-19 $\mathrm{K}$ allows a clear resolution of bulk $T_{\mathrm{g}}$ and the $T_{\mathrm{g}}$ of the pore liquid since in this case, excess liquid is included to illustrate $\Delta T_{\mathrm{g}}$ directly. For all the pore diameters studied, the change in $C_{p}$ from the glass to the melt is smeared out or broadened for the pore liquid relative to the bulk. This is especially

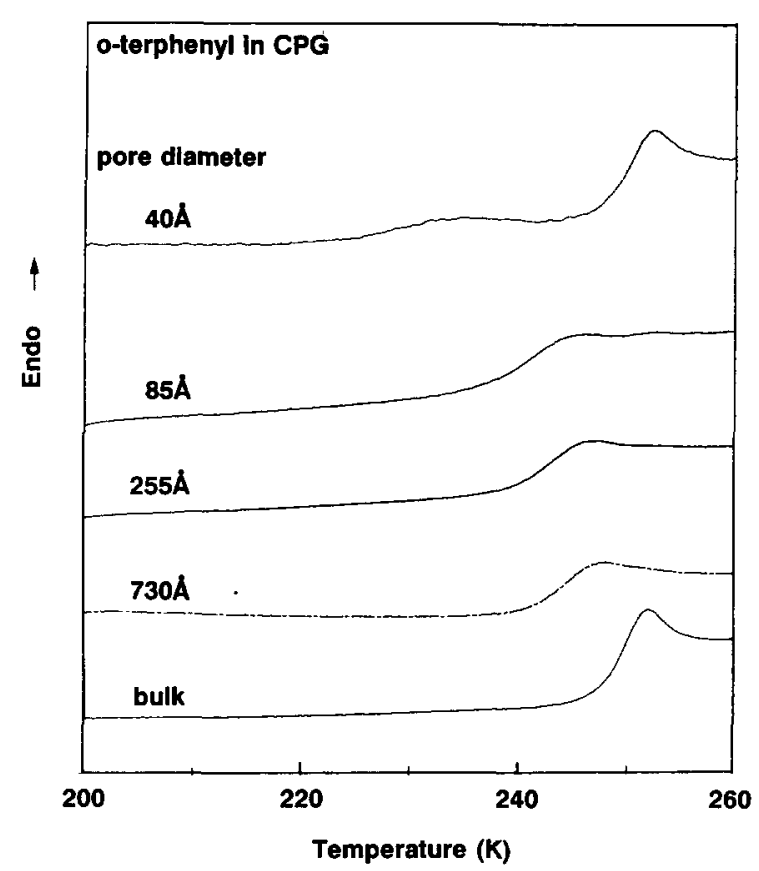

Fig. 1. Data showing the reduction in the glass-to-liquid transition temperature, $T_{\mathrm{g}}$, of o-terphenyl confined in controlled pore glasses of pore diameters of $40,85,255$ and $730 \AA$, with comparison to bulk, pure o-terphenyl shown in the bottom scan. 
Table 2

$T_{\mathrm{g}}, \Delta T_{\mathrm{g}}, \Delta C_{p}$ and $\Delta T_{\mathrm{m}}$ as a function of pore size

\begin{tabular}{|c|c|c|c|c|c|}
\hline Substance & Diameter $(\AA)$ & $T_{\mathrm{g}}(\mathrm{K})$ & $\Delta T_{\mathrm{g}}(\mathrm{K})$ & $\Delta C_{p}(\mathrm{cal} / \mathrm{g} \mathrm{deg})$ & $\Delta T_{\mathrm{m}}(\mathrm{K})$ \\
\hline \multirow[t]{6}{*}{ o-terphenyl } & 40 & 229.9 & 18.2 & 0.09 & n.d. ${ }^{\text {a) }}$ \\
\hline & 85 & $239.3 \pm 0.5^{b)}$ & 8.8 & $0.13 \pm 0.022^{b)}$ & \\
\hline & 156 & 241.9 & 6.2 & 0.10 & \\
\hline & 255 & 242.3 & 5.8 & 0.10 & \\
\hline & 730 & $243.7 \pm 0.6^{b)}$ & 4.4 & $0.11 \pm 0.021^{b)}$ & \\
\hline & bulk & $248.1 \pm 0.5^{b)}$ & - & $0.13 \pm 0.021^{b)}$ & \\
\hline \multirow[t]{5}{*}{ Benzyl alcohol } & 40 & 161.5 & 7.2 & 0.14 & $-^{c)}$ \\
\hline & 85 & 165.6 & 3.1 & 0.11 & 25.3 \\
\hline & 156 & 166.7 & 2.0 & 0.13 & 12.6 \\
\hline & 730 & 166.0 & 2.2 & 0.15 & $\sim 4$ \\
\hline & bulk & 168.7 & - & $-0.12^{d)}$ & - \\
\hline
\end{tabular}

a) n.d. = not determined for o-terphenyl, see text.

b) Mean of data \pm one standard deviation.

c) No melting peak was observed for benzyl alcohol in the $40 \AA$ pores.

d) Value is approximate due to difficulty in preparing a quenched glass in pure benzyl alcohol.

true for the $40 \AA$ pore diameter CPG, which also has low pore volume $\left(0.13 \mathrm{~cm}^{3} / \mathrm{g}\right)$, resulting in the magnitude of the transition being small compared to the other pore diameters studied.

The midpoint of the transition region of the curve was interpreted as $T_{\mathrm{g}}$ and the values of $T_{\mathrm{g}}$, $\Delta T_{g}$ and $\Delta C_{p}$ are given in table 2 for both oterphenyl and benzyl alcohol. Measured values for $\Delta T_{\mathrm{m}}$ are also included in table 2 for benzyl alcohol

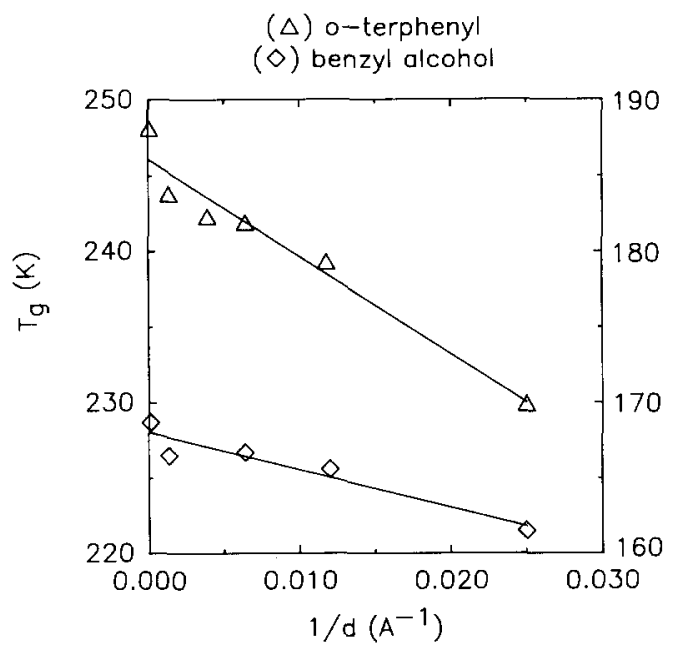

Fig. 2. $T_{\mathrm{g}}$ versus $1 / d$ for o-terphenyl and benzyl alcohol confined in controlled pore glasses with diameters from $40-730$ $\AA$. The bulk $T_{\mathrm{B}}$ is given on the far left axis $(d \rightarrow \infty)$ for reference. so that a comparison can be made in the magnitude of the shifts in the crystalline melting transition and the glass transition. For o-terphenyl, crystallization is more difficult and often requires long annealing periods [18]; thus the $\Delta T_{\mathrm{m}}$ for o-terphenyl was not studied in this work.

In fig. 2 , the $T_{\mathrm{g}}$ is plotted versus $1 / d$. Several observations are apparent from these data which we present but cannot fully explain at this time. For example, at equivalent pore diameters, the shifts in $T_{\mathrm{g}}$ for o-terphenyl are greater than those observed for benzyl alcohol. Also, in the case of benzyl alcohol, the shifts in $T_{\mathrm{g}}$ appear to more closely approach zero at large pore size $(\sim 2 \mathrm{~K}$ at the $730 \AA$ size) than for o-terphenyl $(-4 \mathrm{~K}$ at the $730 \AA$ size). A similar feature for the two sets of data is that the $\Delta C_{p}$ of the transition is not affected by the system size but is comparable to that measured for the bulk liquid.

\section{Discussion}

The reduction in the glass-transition temperature observed for liquids confined in restricted geometries is similar in direction, but smaller in magnitude, than the reduction of the first-order crystalline melting point, reported in detail in related work [2]. For example, benzyl alcohol in 
the $85 \AA$ pores gave a $\Delta T_{\mathrm{m}}$ of $\sim 25 \mathrm{~K}$, while $\Delta T_{\mathrm{g}}$ was only $3 \mathrm{~K}$ (Table 2 ).

The shifts in $T_{\mathrm{g}}$ observed for liquids vitrified in small pores were compared with those obtained by the microemulsion method of Angell and coworkers [5-7], and found to be very different. In their method, a similar size scale is formed during the vitrification of simple liquids dispersed in glass-forming microemulsions, with domain sizes estimated to be $\sim 20-60 \AA$ (from transmission electron microscopy studies) [5]. However, the very broad transition range of the vitrified liquid in the microemulsion is shifted only slightly $(2 \mathrm{~K})$ and is above the bulk $T_{\mathrm{g}}$ Thus, size effects do not appear to be significant [5], within the experimental error (due to the broadness of the transition). We do not know the reason for the different results in these two systems, but suggest that the fixed nature of the controlled pore-glass geometry is a more ideal system with which to study the effect of size on $T_{\mathrm{g}}$. As shown previously in fig. 1, the transitions observed for the pore liquid confined in CPGs are well-defined and unambiguous.

Why does a small system size so strongly influence the glass-transition temperature of oterphenyl and benzyl alcohol? Some possible theoretical and experimental explanations for the observed reduction in $T_{\mathrm{g}}$ are now presented. Entropy models $[12,13]$ of the glass transition would predict the entropy of a liquid in a small pore to be decreased [19], thus shifting the $T_{\mathrm{g}}$ to higher temperatures, in opposition to the experimental behavior described above. To predict the observed shift in $T_{\mathrm{g}}$ to lower temperatures, the entropy at any given temperature must increase. Similarly, based on free volume concepts of the glass transition [8-11], one would expect that free volume should increase to produce the observed shift. Either an increase in entropy or in free volume could be explained if the bulk density of the liquid in the pores is reduced, perhaps as a result of difficulty in packing the molecules. This effect would be more significant for very large molecules like o-terphenyl, and may explain why the observed shifts in $T_{\mathrm{g}}$ for o-terphenyl are larger than for benzyl alcohol. A reduction in bulk density might also occur if the glass is formed under a negative pressure [20]. For o-terphenyl, the pres- sure dependence of $T_{\mathrm{g}}$ has been measured at positive pressures and $T_{\mathrm{g}}$ is found to increase by $20 \mathrm{~K}$ per kilobar $[20,21]$. Thus, very large negative pressure would be required to explain the magnitude of the shifts in $T_{\mathrm{g}}$ observed in this work. This appears unlikely since the cavitation pressure for o-terphenyl is -70 bar [20]. The suggestion [17] that $T_{\mathrm{g}}$ may be, reduced due to plasticization of the organic glass by the trimethylsilyl groups on the surface of the CPG was discarded based on data showing similar shifts in $T_{\mathrm{g}}$ for benzyl alcohol in the untreated CPG samples.

\section{References}

[1] G.K. Rennie and J. Clifford, J. Chem. Soc. F1, 73 (1977) 680.

[2] C.L. Jackson and G.B. McKenna, submitted to J. Chem. Phys. 93 (1990) 9002.

[3] D.D. Awschalom and J. Warnock, Phys. Rev. B35 (1987) 6774.

[4] K. Shirahama, M. Kubota, S. Ogawa, N. Wada and T. Watanaba, Phys. Rev. Lett. 64 (1990) 1541.

[5] J. Dubochet, M. Adrian, J. Teixeira, C.M. Alba, R.K. Kadiyala, D.R. MacFarlane and C.A. Angell, J. Phys. Chem. 88 (1984) 6727.

[6] C.A. Angell, R.K. Kadiyala and D.R. MacFarlane, J. Phys. Chem. 88 (1984) 4593.

[7] D.R. MacFarlane and C.A. Angell, J. Phys. Chem. 86 (1982) 1927.

[8] R. Simha and T. Somcynsky, Macromolecules 2 (1971) 342.

[9] R.E. Robertson, R. Simha and J.G. Curro, Macromolecules 18 (1985) 2239.

[10] J.G. Curro, R.R. LaGasse and R. Simha, Macromolecules 15 (1982) 1621.

[11] G.B. McKenna, in: Comprehensive Polymer Science, Vol. 2, Polymer Properties, eds. C. Booth and C. Price (Pergammon, Oxford, 1989) p. 311.

[12] J.H. Gibbs and E.A. DiMarzio, J. Chem. Phys. 28 (1958) 373.

[13] E.A. DiMarzio and J.H. Gibbs, J. Chem. Phys. 28 (1958) 807.

[14] G. Braun and A.J. Kovacs, Phys. Chem. Glasses 4 (1963) 152.

[15] A.C.-M. Yang and E.J. Kramer, J. Poly. Sci. Polym. Phys. Ed. 23 (1985) 1353.

[16] H.R. Brown, E.J. Kramer and R.A. Bubeck, J. Polym. Sci. Polym. Phys. Ed. 25 (1987) 1765.

[17] W. Haller, Nature 206 (1966) 693.

[18] S.S. Chang and A.B. Bestul, J. Chem. Phys. 56 (1972) 503.

[19] E.A. DiMarzio, personal communication.

[20] C.A. Angell and Z. Qing, Phys. Rev. B39 (1989) 8784.

[21] T. Atake and C.A. Angell, J. Phys. Chem. 83 (1979) 3218. 